\title{
Analysing the concept of diagnostic inertia in hypertension: a cross-sectional study
}

\author{
V. Pallares-Carratalá, ${ }^{1,2}$ I. Bonig-Trigueros, ${ }^{3}$ A. Palazón-Bru, ${ }^{4,5}$ A. Lorenzo-Piqueres, ${ }^{6}$ F. Valls-Roca, ${ }^{7}$ \\ D. Orozco-Beltrán, ${ }^{4}$ V. F. Gil-Guillen ${ }^{4,5}$ Steering Committee ESCARVAL Study*
}

\section{SUMMARY}

Aims: The aim of this study was to quantify diagnostic inertia (DI) when the physician fails to diagnose hypertension and determine its associated factors. Methods: This cross-sectional, observational study involved all patients without a diagnosis of hypertension who had their blood pressure (BP) measured at least three times during the second half of $2010(N=48,605)$. Patients with altered mean BP figures ( $\geq 140 / 90 \mathrm{mmHg}$ ) were considered to experience DI. Secondary variables: gender, atrial fibrillation, diabetes mellitus, dyslipidemia, cardiovascular disease, age and the physician having attended a cardiovascular training course (ESCARVAL). Associated factors were assessed by multivariate logistic regression analysis. Results: Diagnostic inertia was present in 6450 patients $(13.3 \%, 95 \%$ $\mathrm{Cl}$ : 13.0-13.6\%). Factors significantly associated with $\mathrm{DI}$ were: male gender $(\mathrm{OR}=1.46,95 \% \mathrm{Cl}: 1.37-1.55, \mathrm{p}<0.001)$, atrial fibrillation $(\mathrm{OR}=0.73,95 \%$ $\mathrm{Cl}: 0.58-0.92, p=0.007)$, the ESCARVAL cardiovascular course $(O R=0.88$, $95 \% \mathrm{Cl}: 0.81-0.96, p=0.005)$, diabetes mellitus $(\mathrm{OR}=0.93,95 \% \mathrm{Cl}: 0.87-$ $0.99, \quad p=0.016)$, cardiovascular disease $(O R=0.77,95 \% \quad \mathrm{Cl}: 0.67-0.88$, $p<0.001)$ and older age (years) $(18-44 \rightarrow O R=1 ; 45-59 \rightarrow O R=12.45,95 \%$ $\mathrm{Cl}: 11.11-13.94 ; \quad 60-74 \rightarrow \mathrm{OR}=18.11, \quad 95 \% \quad \mathrm{Cl}: \quad 16.30-20.12 ; \quad \geq 75 \rightarrow$ $\mathrm{OR}=20.43,95 \% \mathrm{Cl}: 18.34-22.75 ; \mathrm{p}<0.001)$. The multivariate model had an area under the ROC curve of 0.81 (95\% Cl: $0.80-0.81, p<0.001)$. Conclusions: This study will help clinical researchers differentiate between the two forms of $\mathrm{DI}$ (interpretation of a positive screening test and interpretation of positive diagnostic criteria). The results found here in patients with hypertension suggest that this problem is prevalent, and that a set of associated factors can explain the outcome well $(A \cup C>0.80)$.

\section{Introduction}

In 2001, Phillips introduced the concept of clinical inertia, defining it as failure by the physician to initiate or intensify treatment when this action was indicated (1). This inertia, coupled with poor medication adherence by the patient, is considered the main cause of poor control of chronic diseases such as hypertension (2).

In 2010, Gil-Guillén et al. examined the idea of clinical inertia, developing the concept of diagnostic inertia (DI), defined as the conservative attitude of physicians when interpreting a positive screening test. In other words, when a patient with a positive screening test but without a diagnosis of a specific disease is labelled as 'not sick' by the physician $(3,4)$.

\section{What's known}

The concept of diagnostic inertia, developed in 2010 was considered to be failure in the interpretation of a positive screening test. Four years later the concept was studied in dyslipidemia, with diagnostic inertia being assessed when making a diagnostic confirmation. The prevalence of diagnostic inertia was seen to be very high.

\section{What's new}

We have now examined the concept of diagnostic inertia with the results of more than just one measurement (not a screening test) in patients with hypertension. The proportion of inertia was much lower than that for a screening test. We report certain associated factors that may help understand the possible causes of this inertia.
${ }^{1}$ Health Surveillance Department, Mutual Society of Castellón, Castellón, Spain ${ }^{2}$ Department of Medicine Jaume I University, Castellón, Spain

${ }^{3}$ Internal Medicine Service, La Plana Hospital, Vila-real, Spain ${ }^{4}$ Department of Clinical Medicine, Miguel Hernández University, San Juan de Alicante, Spain

${ }^{5}$ Research Unit, Elda General Hospital, Elda, Spain

${ }^{6}$ Teaching Unit of Primary Health Care, Generalitat Valenciana, Castellón, Spain ${ }^{7}$ Health Centre of Benigánim, Generalitat Valenciana, Benigánim, Spain

\section{Correspondence to: Prof. Antonio Palazón-Bru, PhD, Department of Clinical Medicine, Miguel Hernández University, Carretera de Valencia - Alicante S/N, San Juan de Alicante, Alicante 03550, Spain Tel.: + 34965919449 Fax: + 34965919450 Email: antonio. pb23@gmail.com \\ *See Acknowledgements section.}

Resulting from this derivation of the classical concept by Phillips $(1,3,4)$, several studies have analysed the attitude of physicians when interpreting altered results of a screening test for cardiovascular risk factors (hypertension, diabetes mellitus and dyslipidemia) (5-7). In 2014, Palazón-Bru et al. proposed a derivation of the original concept of DI, classifying as inertia the lack of diagnostic confirmation although the physician has two or more lipid profile measurements for a patient without a diagnosis of dyslipidemia (8). Furthermore, this study undertook a review detailing the main characteristics of studies that had assessed this problem but did not include the concept of DI, both in altered screening results and when two or more lipid profile results were available. The prevalence of this
Disclosures

None. 
problem was shown to be very high in some geographical regions $(8-11)$.

Considering that the concept of DI in the presence of more than one measurement (not a screening test) has only been evaluated in dyslipidemia (8), it is important to analyse this concept in other chronic diseases, such as hypertension. Accordingly, to better understand DI, we conducted a study assessing its prevalence and associated factors in hypertension. With the findings, we can take measures aimed at physicians to prevent DI and thus improve the detection and treatment of high blood pressure and consequently reduce the incidence of cardiovascular disease.

\section{Materials \& methods}

\section{Study population}

The study population comprised patients without hypertension in the Valencian Community (a Mediterranean region on the east coast of Spain), with a minimum of three visits to the health centre with blood pressure (BP) measurements taken at each visit [the number necessary to confirm the diagnosis (12,13)]. This community has approximately 5 million inhabitants and the health system is free and universal. Furthermore, this region has an electronic database for the health system that includes all levels of care, and all drugs have to be prescribed through this system $(8,14)$.

\section{Study design and participants}

This cross-sectional, observational study analysed a sample of patients treated by their primary care physician at their health centre in the Valencian Community during the second half (July to December) of 2010. These patients had to have no diagnosis of hypertension, as seen from the electronic medical record (ICD-9-CM code 401.x or having a prescription for antihypertensive medication). They were also required to have a record of $\mathrm{BP}$ readings taken on at least three visits to the health centre, thus enabling the primary care physician to confirm or rule out the diagnosis of hypertension in accordance with the European guidelines on hypertension management $(12,13)$.

The medical records database was consulted to obtain the patient sample, selecting those patients who met the inclusion criteria.

\section{Variables and measurements}

The primary variable was DI, defined as having mean BP values above normal ( $B P \geq 140 / 90 \mathrm{mmHg}$ ) $(12,13)$. In other words, if a patient had abnormal readings and was undiagnosed, this implied failure by the primary care physician to diagnose the patient with hypertension. Note that the cut-off point of $130 / 80 \mathrm{mmHg}$ was not used for diabetic patients or those patients who had cardiovascular disease because it is the goal of the treatment, i.e. after they have been diagnosed with hypertension, and our patients had not been diagnosed with this condition (see Study Design and Participants).

Secondary variables were: gender, atrial fibrillation, diabetes mellitus, dyslipidemia, cardiovascular disease (12), age (18-44, 45-59, 60-74 and $\geq 75$ years) and ESCARVAL training. The diagnoses were obtained from the electronic medical records using the ICD-9-CM codes for each disease. In addition, for dyslipidemia and diabetes, the drugs prescribed by the primary care physician (lipid-lowering drugs, insulin and oral antidiabetic agents) were reviewed. Gender and age were also obtained from the electronic medical records. The ESCARVAL study documents all the health professionals who have completed the training course, including updates on cardiovascular disease, both for clinical practice and for research (15). Age was categorised following the structure proposed by Palazón-Bru et al. in their study on dyslipidemia (8). In addition, the patients who experienced inertia were then categorised in two groups: those with $\mathrm{BP}$ values $\geq 160 / 100$ and the rest $(12,13)$. Finally, we determined how many patients with diabetes or cardiovascular disease with $\mathrm{BP}$ values $\geq 130 / 80 \mathrm{mmHg}$ had $\mathrm{BP}$ values $\geq 140$ / $90 \mathrm{mmHg}$, because it is important to know how many patients with a target of $130 / 80 \mathrm{mmHg}$ actually had BP values below 140/90 $\mathrm{mmHg}$, perhaps suggesting a lack of knowledge of the guidelines $(12,13)$.

\section{Sample size}

As the sample was extracted from the medical records database, no prior sample size was obtained for consideration in our study. Consequently, we calculated the precision of the sample to estimate a proportion (DI). The sample comprised a total of 48,605 patients. To estimate the prevalence, assuming a type I error of $5 \%$ and a maximum expected proportion, a precision of $0.44 \%$ was obtained.

\section{Statistical methods}

Since all our variables were qualitative, the descriptive analysis was performed using frequencies and percentages. Associated factors were identified through the construction of a logistic regression model in which DI was the dependent variable and all the secondary variables were the independent variables. The adjusted odds ratios (ORs) were then obtained for each of the factors analysed. The 
goodness-of-fit of the model was assessed using the likelihood ratio test and by calculating the area under the ROC curve. Finally, we determined the differences in the patients who experienced inertia between those with $\mathrm{BP}$ values $\geq 160 / 100 \mathrm{mmHg}$ and the rest using the chi-squared test. The significance level was set at 5\% and for each relevant parameter; its associated confidence interval was calculated. The statistical software used was IBM SPSS Statistics 19.

\section{Ethical issues}

The study was approved by the Public Health Ethics Committee of the Valencian Community. This committee allowed analysis of the data from the medical records in an anonymised and encrypted fashion. Access to information was completely restricted, ensuring that the extracted data could not be made public. No consent was sought from the patients included in the study because by obtaining the data in a completely anonymous manner, it was impossible to contact the patients. The Committee approved this procedure. A more detailed description of this entire process can be seen in the study by PalazónBru et al. (8).

\section{Results}

A total of 48,605 patients without hypertension and with a sufficient number of $B P$ readings to make this diagnosis attended their health centre in the Valencian Community in the second half of 2010. Of this number, 6450 patients presented DI $(13.3 \%$, 95\% CI: $13.0-13.6 \%)$, of whom 468 (7.2\%; 95\% CI: $6.6-7.9 \%$ ) had BP values $\geq 160 / 100 \mathrm{mmHg}$. Moreover, among patients with BP values $\geq 130 /$ $80 \mathrm{mmHg}$ and with cardiovascular disease or diabetes $(n=5781)$, a total of 2400 patients had BP readings above $140 / 90 \mathrm{mmHg} \quad(41.5 \%, 95 \%$ CI: 40.2-42.8\%).

Table 1 shows the descriptive characteristics of the sample. There were fewer men (22.9\%), a high prevalence of cardiovascular risk factors (diabetes, $18.4 \%$; dyslipidemia, $24.8 \%$ ) and $2.7 \%$ of the patients had cardiovascular disease. Most of the patients ranged in age between 18 and 44 years (55.7\%).

Analysis of the factors associated with DI obtained through the multivariate model produced the following profile: male gender $(\mathrm{OR}=1.46, \mathrm{p}<0.001)$, not being diagnosed with atrial fibrillation $(\mathrm{OR}=0.73$, $\mathrm{p}=0.007$ ), having a health professional who had not taken the ESCARVAL training course $(\mathrm{OR}=0.88$, $\mathrm{p}=0.005)$, not having a diagnosis of diabetes $(\mathrm{OR}=0.93, \mathrm{p}=0.016)$ or cardiovascular disease $(\mathrm{OR}=0.77, \mathrm{p}<0.001)$, and older age $(\mathrm{p}<0.001)$.
The model was highly significant $(\mathrm{p}<0.001)$ and exhibited an area under the ROC curve of 0.81 (95\% CI: $0.80-0.81, \mathrm{p}<0.001$; Figure 1).

Analysis of the differences in patients experiencing DI (Table 2) showed that patients with higher BP readings $(\geq 160 / 100 \mathrm{mmHg})$ had a significantly $(\mathrm{p}<0.05)$ lower prevalence of dyslipidemia $(36.6 \%$ vs. $44.2 \%, \mathrm{p}<0.001)$ and were older $(\mathrm{p}=0.014)$. The remaining variables showed no significant differences between the two DI groups.

\section{Discussion}

\section{Summary}

By having been carried out in a different disease, in this case hypertension, this study reinforces the concept of DI developed by Palazón-Bru et al. conducted in dyslipidemia (8). The proportion of DI in our study was $13.3 \%$, indicating that primary care physicians did not diagnose hypertension in approximately one in seven patients who met the criteria for this condition. Factors associated with DI were also identified. Furthermore, among patients experiencing DI, one in 14 had BP values above 160/ $100 \mathrm{mmHg}$. Indeed, differences were found between those with BP values above 160/100 $\mathrm{mmHg}$ and the rest.

\section{Strengths and limitations}

The main strength of this work is that it reinforces the concept of DI using two or more determinations of the relevant control parameter (depending on the disease) (8), evaluating DI in a novel way in hypertension. Moreover, the use of an information source encompassing all levels of medical care, in a region of nearly five million inhabitants, minimised any potential information bias. In addition, the area under the ROC curve of the multivariate model was greater than $80 \%$, indicating that, although we did not analyse the number of medications a patient was already taking, the number of chronic conditions (comorbidities) already diagnosed, the presence of chronic kidney disease, or socioeconomic status the factors found were strongly related to DI. Finally, the error in estimating the proportion of inertia was less than $1 \%$, which is very satisfactory.

Regarding limitations, since we only included patients attending their health centre during a specific period of time, there may have been selection bias. In addition, we only included patients who had a record of $\mathrm{BP}$ readings, i.e. those for whom the healthcare professional had recorded these values in the electronic medical record. Given that we cannot minimise this bias, it would be interesting to repeat 
Table 1 Analysis of patients who experienced diagnostic inertia for hypertension in a Spanish region, 2010 data

\begin{tabular}{|c|c|c|c|c|}
\hline Variable & $\begin{array}{l}\text { Total } \\
n=48,605 \\
n(\%)\end{array}$ & $\begin{array}{l}\text { Inertia } \\
n=6450 \\
n(\%)\end{array}$ & $\begin{array}{l}\text { Adj. OR for inertia } \\
(95 \% \mathrm{Cl})\end{array}$ & $p$ \\
\hline Male gender & $11,152(22.9)$ & $3348(51.7)$ & $1.46(1.37-1.55)$ & $<0.001$ \\
\hline Atrial fibrillation & $427(0.9)$ & $102(1.6)$ & $0.73(0.58-0.92)$ & 0.007 \\
\hline ESCARVAL training & $6422(13.2)$ & $729(11.3)$ & $0.88(0.81-0.96)$ & 0.005 \\
\hline Diabetes & $8928(18.4)$ & $2243(34.7)$ & $0.93(0.87-0.99)$ & 0.016 \\
\hline Dyslipidemia & $12,046(24.8)$ & $2818(43.5)$ & $0.99(0.93-1.05)$ & 0.637 \\
\hline Cardiovascular disease & $1336(2.7)$ & $317(4.9)$ & $0.77(0.67-0.88)$ & $<0.001$ \\
\hline \multicolumn{5}{|l|}{ Age (years) } \\
\hline $18-44$ & $27,090(55.7)$ & $529(8.2)$ & 1 & $<0.001$ \\
\hline $45-59$ & $5520(11.4)$ & $1197(18.5)$ & $12.45(11.11-13.94)$ & \\
\hline $60-74$ & $9377(19.3)$ & $2683(41.5)$ & $18.11(16.30-20.12)$ & \\
\hline$\geq 75$ & $6618(13.6)$ & 2041 (31.5) & $20.43(18.34-22.75)$ & \\
\hline
\end{tabular}

OR were adjusted for gender, atrial fibrillation, ESCARVAL training, diabetes, dyslipidemia, cardiovascular disease and age. Goodnessof-fit of the model: $\chi^{2}=7845.84, p<0.001$. Area under the ROC curve: $0.81 . n(\%)$, absolute frequency (relative frequency or percentage); Adj. OR, adjusted odds ratio; $\mathrm{Cl}$, confidence interval.

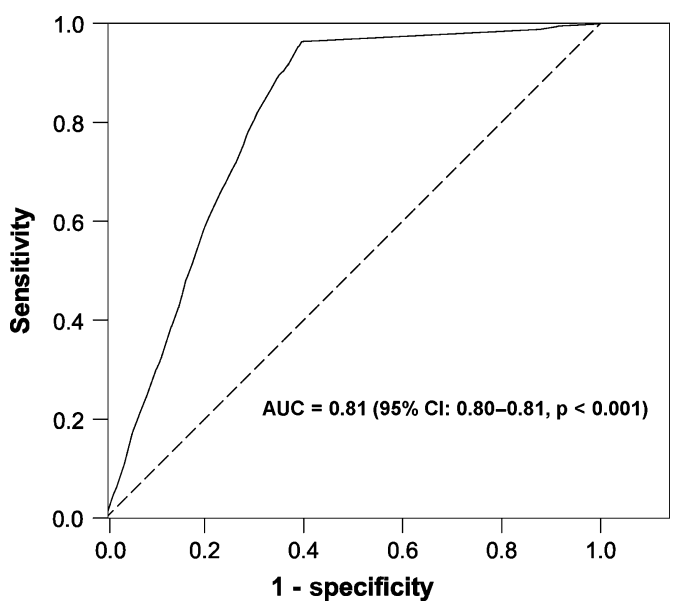

Figure 1 ROC curve for the multivariate logistic regression model. AUC, area under the ROC curve; CI, confidence interval

this study in the general population and with primary data sources with manually recorded BP values. Another possibility might be to synchronise the BP measuring devices with the electronic medical record to automatically record the measurement. In our region, this procedure is already in use for lipid measurements.

\section{Comparison with the existing literature}

When we compare our results with those of other authors, we must do so with those who have studied DI in the interpretation of BP screenings. This issue has been assessed in a preventive programme by two working groups. The first was conducted in the general population (4) and the second was restricted to the obese population (5). These studies found a proportion of DI of $32.5 \%$ and $70.2 \%$, respectively $(4,5)$. Our magnitude is far below the values obtained by these authors, although we must bear in mind that we were working with three or more BP readings and these authors only analysed the interpretation of one altered screening test. Thus, we cannot compare the results, as the clinical environments and methodologies differ. This same reasoning can be extrapolated to the factors associated with DI, in which the other authors found an increased cardiovascular risk associated with this problem, whereas we only coincide with this aspect in that older age is associated with an increased likelihood of DI. Finally, it was very satisfying to find that most patients who experienced DI had BP values in the Stage I hypertension category $(92.8 \%)(12,13)$. This was much lower in dyslipidemia with DI in the interpretation of diagnostic screenings (52.3\%) (7). This suggests that in the diagnosis of hypertension, the primary care physician is more aware of the elevated BP values when diagnosing a patient. Furthermore, in patients with DI, when we analysed the differences between the highest BP values and the rest, it was notable that the prevalence of most cardiovascular risk factors was similar, except for age and dyslipidemia. In other words, this appears to indicate that the healthcare professional takes into account the BP values themselves rather than the cardiovascular risk factors. Fortunately, the very high BP values in the patients experiencing DI were present in only one out of fourteen patients. 
Table 2 Analysis by BP groups of patients who experienced diagnostic inertia in a Spanish region, 2010 data

\begin{tabular}{|c|c|c|c|}
\hline Variable & $\begin{array}{l}\mathrm{BP}<160 / 100 \mathrm{mmHg} \\
n=5983 \\
n(\%)\end{array}$ & $\begin{array}{l}\mathrm{BP} \geq 160 / 100 \mathrm{mmHg} \\
n=467 \\
n(\%)\end{array}$ & $p$ \\
\hline Male gender & $2866(47.9)$ & $237(50.7)$ & 0.236 \\
\hline Atrial fibrillation & $95(1.6)$ & $7(1.5)$ & 0.882 \\
\hline ESCARVAL training & $682(11.4)$ & $42(9.0)$ & 0.113 \\
\hline Diabetes & $2086(34.9)$ & $156(33.4)$ & 0.523 \\
\hline Dyslipidemia & $2647(44.2)$ & $171(36.6)$ & $<0.001$ \\
\hline Cardiovascular disease & $298(5.0)$ & $19(4.1)$ & 0.380 \\
\hline \multicolumn{4}{|l|}{ Age (years) } \\
\hline $18-44$ & $496(8.3)$ & $33(7.1)$ & 0.014 \\
\hline $45-59$ & $1121(18.7)$ & $76(16.3)$ & \\
\hline $60-74$ & $2504(41.9)$ & 179 (38.3) & \\
\hline$\geq 75$ & $1862(31.1)$ & $179(38.3)$ & \\
\hline
\end{tabular}

p-values were obtained using the $\chi^{2}$ test. BP, blood pressure; $n(\%)$, absolute frequency (relative frequency or percentage).

\section{Implications for research and practice}

This work further strengthens the concept of DI, in which a distinction is created between inertia in the interpretation of screening and inertia in confirming a diagnosis. In other words, DI encompasses these two concepts, which must be assessed separately, and we must be cautious in their interpretation.

Lines of research are opening up that will help us determine the causes of this inertia. All previous publications have suggested that qualitative studies can help to reduce this proportion and provide a good basis for designing training programmes for primary care physicians to update their knowledge in cardiovascular disease $(5-7,14)$. We believe this would be a good line of investigation by which we could reduce DI, achieving improved control of hypertension in our community, and therefore a possible decrease in the incidence of cardiovascular diseases. In the future, it would be interesting to determine the outcomes of these patients suffering DI, especially in those with BP values >160/ $100 \mathrm{mmHg}$.

\section{Conclusion}

This study helped us differentiate between DI when interpreting an altered screening test and when failing to diagnose hypertension when there were an adequate number of readings to do so. DI encompasses these two concepts. The results of three BP measurements were used for the diagnosis of hypertension, obtaining a much lower rate of DI than that found with the interpretation of one screening test (a single BP reading). Moreover, associated factors that provide a preliminarily understanding of the possible causes of this inertia were identified.

\section{Acknowledgments}

This study was partly financed by the Generalitat Valenciana and nonprofit research grants from the pharmaceutical industry (Boehringer Ingelheim, Merck Sharp \& Dohme Corp., Almirall, Bayer, Novo Nordisk and Sanofi-Aventis). The financing entities played no role in the study design, data collection and analysis, the decision to publish the results or in the manuscript preparation. The authors are grateful to the Conselleria de Sanitat for the chance to carry out this study. Finally, the authors thank Maria Repice and Ian Johnstone for their help preparing the English version of this paper.

Steering Committee ESCARVAL Study: Vicente Francisco Gil-Guillén, Domingo Orozco-Beltrán, Vicente Pallarés-Carratalá, Francisco Valls-Roca, Carlos Sanchis-Domenech, José María Martín-Moreno, Josep Redón, Jorge Navarro-Pérez, Antonio Fernández-Giménez, Ana María Pérez-Navarro.

\section{Author contributions}

VP and IB designed the study and drafted the manuscript. AP helped draft and critically reviewed the manuscript, and performed the statistical analysis. AL, FV, DO and VFG participated in the study design and critically reviewed the manuscript. All the authors agreed with the final version of the paper submitted to be considered for publication. 


\section{References}

1 Phillips LS, Branch WT, Cook CB et al. Clinical inertia. Ann Intern Med 2001; 135: 825-34 Review.

2 Martínez-Orozco MJ, Perseguer-Torregrosa Z, GilGuillén VF, Palazón-Bru A, Orozco-Beltran D, Carratalá-Munuera C. Suitability of antiplatelet therapy in hypertensive patients. J Hum Hypertens 2015; 29: $40-5$.

3 Lebeau JP, Cadwallader JS, Aubin-Auger I et al. The concept and definition of therapeutic inertia in hypertension in primary care: a qualitative systematic review. BMC Fam Pract 2014; 15: 130.

4 Gil-Guillén V, Orozco-Beltrán D, Pérez RP et al. Clinical inertia in diagnosis and treatment of hypertension in primary care: quantification and associated factors. Blood Press 2010; 19: 3-10.

5 Martínez-St John DR, Palazón-Bru A, Gil-Guillén VF et al. Diagnostic inertia in obesity and the impact on cardiovascular risk in primary care: a cross-sectional study. Br J Gen Pract 2015; 65: e454-9.

6 Sepehri A, Palazón-Bru A, Gil-Guillén VF et al. Diabetes screening: a pending issue in hypertense/ obese patients. PeerJ 2015; 3: e914.

7 Palazón-Bru A, Sepehri A, Ramírez-Prado D et al. Diagnostic inertia in dyslipidaemia: results of a preventative programme in Spain. PeerJ 2015; 3: el109.

8 Palazón-Bru A, Gil-Guillén VF, Orozco-Beltrán D et al. Is the physician's behavior in dyslipidemia diagnosis in accordance with guidelines? Cross-sectional ESCARVAL study PLoS ONE 2014; 9: e91567.

9 Landzberg JS, Heim CR. Physician recognition and treatment of hypercholesterolemia. Arch Intern Med 1989; 149: 933-5.

10 Levin SJ, Ornstein SM. Management of hypercholesterolemia in a family practice setting. J Fam Pract 1990; 31: 613-7.

11 Saturno Hernández PJ, Gascón Cánovas JJ, Bueno JM, Alcaraz J, Martínez Martínez P. El diagnóstico de las dislipemias en atención primaria: un servicio a mejorar. Resultados de una evaluación multicéntrica. Aten Primaria 2000; 25: 82-8.

12 Graham I, Atar D, Borch-Johnsen K et al.; European Society of Cardiology (ESC); European Association for Cardiovascular Prevention and Rehabilitation (EACPR); Council on Cardiovascular Nursing; European Association for Study of Diabetes (EASD); International Diabetes Federation Europe (IDF-Europe); European Stroke Initiative (EUSI); Society of Behavioural Medicine (ISBM); European Society of Hypertension (ESH); WONCA Europe (European Society of General Practice/
Family Medicine); European Heart Network (EHN); European Atherosclerosis Society (EAS). European guidelines on cardiovascular disease prevention in clinical practice: full text. Fourth Joint Task Force of the European Society of Cardiology and other societies on cardiovascular disease prevention in clinical practice (constituted by representatives of nine societies and by invited experts). Eur J Cardiovasc Prev Rehabil 2007; 14(Suppl. 2): S1-113.

13 Mancia G, Laurent S, Agabiti-Rosei E et al. Reappraisal of European guidelines on hypertension management: a European Society of Hypertension Task Force document. Blood Press 2009; 18: 308-47.

14 Rico-Ferreira P, Palazón-Bru A, Calvo-Pérez M, Gil-Guillén VF. Nonadherence to guidelines for prescribing antibiotic therapy to patients with tonsillitis or pharyngotonsillitis: a cross-sectional study. Curr Med Res Opin 2015; 31: 1319-22.

15 Gil-Guillén V, Hermida E, Pita-Fernandez S et al. A cardiovascular educational intervention for primary care professionals in Spain: positive impact in a quasi-experimental study. Br J Gen Pract 2015; 65: e32-40.

Paper received October 2015, accepted April 2016 